\title{
Leitfaden der APT „Exposition von Betreuungs- und Begleitpersonen“
}

Arbeitsgemeinschaft

Physik und Technik

Gemäß StrlSchV §§122 und 124 sind

Betreuungs- und Begleitpersonen vor dem
Betreten des Kontrollbereichs über mögliche Gefahren aufzuklären und deren Exposition zu beschränken. Zudem sollen geeignete schriftliche Hinweise angeboten und auf Wunsch ausgehändigt werden. Die APT hat deshalb einen Leitfaden zum Umgang mit Betreuungs- und Begleitpersonen ver- fasst und durch ein Merkblatt zur Information der betroffenen Personen ergänzt.

Den Leitfaden finden Sie unter: www.apt.drg.de und www.vmtb.de. 